\begin{tabular}{|c|c|c|c|}
\hline Article Info & \multicolumn{2}{|c|}{ RESEARCH ARTICLE $\quad$ ARAŞTIRMA MAKALESİ } & \\
\hline Title of Article & \multicolumn{2}{|c|}{$\begin{array}{c}\text { Evaluation of Investment Alternatives With } \\
\text { Analytical Network Process Method For A } \\
\text { Sustainable Green Campus }\end{array}$} & \\
\hline $\begin{array}{l}\text { Correspondig } \\
\text { Author }\end{array}$ & \multicolumn{2}{|c|}{$\begin{array}{l}\text { Tamer EREN } \\
\text { Krıkkale Üniversitesi, Mühendislik ve Mimarlık Fakültesi, Endüstri Mühendisliği Bölümü } \\
\text { tamereren@gmail.com }\end{array}$} & \\
\hline $\begin{array}{l}\text { Received } \\
\text { DateAccepted }\end{array}$ & \multicolumn{2}{|l|}{$\begin{array}{l}28.06 .2021 \\
13.09 .2021\end{array}$} & \\
\hline Doi Number & \multicolumn{2}{|c|}{ https://doi.org/10.35674/kent.959000 } & \\
\hline Author / Authors & $\begin{array}{l}\text { Selma YAPICI } \\
\text { Nursena ORAL } \\
\text { Rabia YUMUŞAK } \\
\text { Tamer EREN }\end{array}$ & $\begin{array}{l}\text { ORCID: } 0000-0002-5172-6739 \\
\text { ORCID: } 0000-0002-9517-5086 \\
\text { ORCID: } 0000-0002-0257-939 X \\
\text { ORCID: } 0000-0001-5282-3138\end{array}$ & \\
\hline How to Cite & \multicolumn{2}{|c|}{$\begin{array}{l}\text { Yapıcı, S., Oral, N., Yumuşak, R., Eren, T. (2021). Sürdürülebilir Yeşil Kampüs İçin } \\
\text { Analitik Ağ Prosesi Yöntemi İle Yatırım Alternatiflerinin Değerlendirilmesi , Kent } \\
\text { Akademisi, Volume, 14, Issue 3, Pages, 777-788 }\end{array}$} & $\begin{array}{l}\text { emisi } \\
\text { demyy }\end{array}$ \\
\hline
\end{tabular}

\title{
Sürdürülebilir Yeşil Kampüs için Analitik Ağ Prosesi Yöntemi ile Yatırım Alternatiflerinin Değerlendirilmesi
}

ABSTRACT:

There are severe problems in Turkey due to reasons such as global warming and climate change. Although cities have specific needs in combating the harmful effects of climate change, and there is no single policy that will serve all purposes, it is possible with analytical methods that the measures to be taken are optimal under current conditions. Therefore, it is necessary to optimally evaluate various opportunities on limited resources to gain knowledge and experience applications through global networks. In the study, the current opportunities were evaluated, the adverse effects of global climate change brought about by urbanization were examined, alternative solutions were sought, and a model was proposed for critical decision problems with an analytical method. In the proposed solution model, investment alternatives for a project of this nature in Kırıkkale University Central Campus were evaluated in order to reduce the adverse effects of the society on the environment by implementing the sustainable green campus project, which includes all of the green roof, vertical garden, sustainable education, electric vehicles, and solar panels. Prioritization based on various criteria (installation costs, skilled labor costs, water efficiency, energy efficiency, time, carbon emissions, and oxygen production) for the realization of the projects was made with the Analytical Network Process (ANP) method. In the study, the Kırıkkale University campus was determined as the Vertical Garden Project, the first project envisaged to be implemented in the transition process to a sustainable green campus. It aimed to be a pioneer in green campus projects to be made in the future.

KEYWORDS: Sustainability, green campus, analytical network process, global climate change, investment assessment.

${ }^{1}$ M. Sc. Candidate, Kirıkale University, Faculty of Engineering and Architecture, Department of Industrial Engineering, selmayapc@gmail.com

${ }^{2}$ M. Sc. Candidate, Kırıkkale University, Faculty of Engineering and Architecture, Department of Industrial Engineering, nursenadige@gmail.com

${ }^{3}$ M. Sc., Kırikkale University, Faculty of Engineering and Architecture, Department of Industrial Engineering, rabiayumusak95@gmail.com

${ }^{4}$ Prof. Dr., Kırıkkale University, Faculty of Engineering and Architecture, Department of Industrial Engineering, tamereren@gmail.com 
ÖZ:

Türkiye"ede küresel ısınma, iklim değişikliği gibi nedenlerden dolayı ciddi sorunlar yaşanmaktadır. Şehirlerin iklim değişikliğinin olumsuz etkileriyle mücadele edilmesinde kendine özel ihtiyaçları olmasına ve tüm amaçlara hizmet edecek tek bir politika bulunmamasına rağmen, alınacak tedbirlerin mevcut şartlar altında optimal olması analitik yöntemlerle mümkündür. Bu yüzden küresel ağlar yoluyla bilgi edinmek ve uygulamaları deneyimlemek adına çeşitli fırsatları kısıtlı kaynaklar için optimal bir şekilde değerlendirmek gerekmektedir. Yapılan çalışmada mevcut firsatlar değerlendirilerek, şehirleşmenin beraberinde getirdiği küresel iklim değişikliğinin çevreye verdiği olumsuz etkiler incelenmiş̧ir ve alternatif çözüm arayışına girilerek kritik karar problemlerine analitik bir yöntemle model önerisinde bulunulmuştur. Önerilen çözüm modelinde, yeşil çatı, dikey bahçe, sürdürülebilir eğitim, elektrikli taşıtlar ve güneş panellerinin tamamını barındıran sürdürülebilir yeşil kampüs projesini hayata geçirerek toplumun çevreye olumsuz etkilerini azaltmak için Kırıkkale Üniversitesi Merkez Kampüsü'nde bu nitelikteki bir projenin yatırım alternatifleri değerlendirilmiştir. Projelerin hayata geçirilmesi için çeşitli kriterlere (kurulum maliyetleri, nitelikli iş gücü maliyetleri, su verimliliği, enerji verimliliği, zaman, karbon emisyonu ve oksijen üretimi) bağli önceliklendirmeler Analitik A $\breve{g}$ Prosesi (ANP) yöntemi ile yapılmıştır. Yapılan çalışmada Kırıkkale Üniversitesi kampüsünün, sürdürülebilir yeşil kampüse geçiş sürecinde hayata geçirilmesi öngörülen ilk proje Dikey Bahçe Projesi olarak belirlenerek gelecekte yapılacak yeşil kampüs projelerine öncü olması hedeflenmiştir.

ANAHTAR KELIMELER: Sürdürülebilirlik, yeşil kampüs, analitik ağ prosesi, küresel iklim değişikliği, yatırım değerlendirmesi.

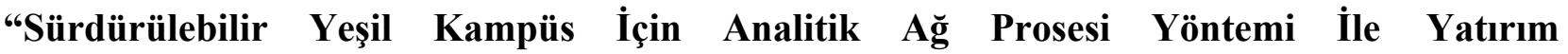 Alternatiflerinin Değerlendirilmesi”}

\section{GíRiş̧:}

Sanayi devrimi ile süregelen arazi kullanımı değişiklikleri, fosil yakıtların kullanılması ve ormansızlaşma gibi insan etkinlikleri sonucunda önemli sera gazlarının atmosferdeki birikimleri hızla artmaktadır. Tüm bu durumlar küresel iklim değişikliğine zemin hazırlamaktadır. Dünyada şehirleşme süreci ile küreselleşme kavramı artmış iklim değişikliği önemli bir problem haline gelmiştir. Bu durumun gün geçtikçe daha tehlikeli bir hal almasıyla birlikte dünyada çözüm arayışları başlamıştır. Böylelikle sürdürülebilir ekolojik projelerin zamanla geliştirilerek küreselleşmenin yarattı̆̆ı sorunlara çözüm olması hedeflenmiştir.

Üniversite gibi büyük kurumlar, sürdürülebilir ve ekolojik uygulamalar ile sürdürülebilir bir yaşam biçiminin yaygınlaşması adına aktif görev alırlar. Böylelikle üniversitelerin yol gösterici ve yenilikçi olma rollerinden dolayı sürdürülebilir ve ekolojik kampüs uygulamaları dünya genelinde hızla yaygınlaşmaya başlamıştır. Sürdürülebilir kampüslere olan ilginin artmasıly beraber uluslararası indeksler kullanılmaya başlamıştır. Yeşil Lig (Green League), Çevresel ve Sosyal Sorumluluk İndeksi (Environmental and Social Responsibility Index) ve Yeşil Ölçüm (GreenMetric) değerlendirme yöntemleri (Suwartha ve Sari, 2013) örnek verilebilir. İndeksler incelendiğinde sürdürülebilir kampüs uygulamalarında ilk olan ve en çok kullanılan UI GreenMetric sıralama modelidir. Bu modelin üniversite yöneticileri ve çalışanlarına enerji, su yönetimi, küresel ısınma ve yeşil ulaşım gibi çeşitli sürdürülebilirlik odaklı ekolojik konularda farkındalık oluşturması hedeflenmiştir. Dünyanın ısıl dengesini bozan karbondioksit gibi sera etkisi yaratan gazlar, denizlerin ve yer kabuğunun ortalama sıcaklığını arttırmasına sebep olan küresel isınma, kritik bir çevre sorunudur. Bu sorun kapsamında "enerji ve iklim değişiklikleri" başlığı altında yer alan "enerji tasarrufu", "sera gazı emisyonu azaltma ve uyum politikası", "kampüs içi karbon ayak izi oranı", "yeşil ve akıllı bina uygulamaları" ve "enerji tasarruflu cihaz kullanımı" konularıyla ilişkili uygulamaların, kampüs içerisine uyarlanarak küresel ısınmaya neden olacak unsurları azaltması amaçlanmaktadır (Kaya, Dal ve Aşkın, 2019).

Türkiye"de hayata geçirilen üniversite çalışmaları incelendiğinde doğaya verilen zararı en aza indirgemek adına çevre dostu, daha az enerji tüketen, sürdürülebilir yapı tasarımlarının ön plana çıkması ve ülkemizde bu tip tasarımların yeterli düzeyde olmaması Kırıkkale Üniversitesi Kampüsü"enün sürdürülebilir yeşil kampüse dönüştürülme fikrini ortaya çıkarmıştır. Sürdürülebilir Yeşil Kampüs Projesinin ilk aşamada Kırıkkale Üniversitesi Merkez Kampüsü" nde hayata geçirilmesi planlanmıştır. Proje burada öğrenim gören öğrencileri, görev alan akademik ve idari personelleri aynı zamanda kampüs çevresinde yaşayan her türlü canlının yaşamını kapsamaktadır. Hedef kitlenin yaşam kalitesini 
arttırarak ekolojik dengenin sürdürülebilirliği sağlanacaktır. Bununla birlikte ekonomik olarak incelendiğinde ise ele alınan projenin uzun vadede pozitif bir geri dönüş sağlayacağı düşünülmektedir.

Sürdürülebilir yeşil kampüs için alternatif projeler değerlendirilmiştir. Proje kapsamında sunulan alternatifler; yeşil çatı, dikey bahçe, elektrikli taşıtlar, güneş panelleri ve sürdürülebilir eğitim olarak belirlenmiştir. Projelerin hayata geçirilmesi için çeşitli kriterlere bağlı olarak önceliklendirmelerin yapılması gerekmektedir. Mevcut durum göz önüne alındığında Sürdürülebilir Yeşil Kampüs Projesi için uygulanması öngörülen proje alternatifleri ve bununla ilişkili kriterlerin değerlendirilmesi, karar kriterleri arasındaki ilişkileri göz önüne alan ve tek bir yöne bağlı kalarak modelleme zorunluluğunu ortadan kaldıran Çok Kriterli Karar Verme (ÇKKV) yöntemlerinden ANP yöntemi kullanılarak yapılmıştır. Yapılması planlanan kampüs projesinin, Kırıkkale Üniversitesi Merkez Kampüsüeende sürdürülebilir ekolojik projelere olan ihtiyacın karşılanması için belirlenen alternatiflerin ekonomik faktörler (kurulum maliyetleri, nitelikli iş gücü maliyeti), kaynak verimliliği (su verimliliği, enerji verimliliği ve zaman) ve hava kalitesine etki (karbon emisyonu, oksijen üretimi) kriterleri bazında yapılan karşılaştırmalar ile geleceğe yönelik yatırımlara yol gösterici olması hedeflenmektedir.

\section{Literatür Taraması}

Çalışmanın bu bölümünde Sürdürülebilir Yeşil Kampüs konusunda yapılmış çalışmalara yer verilmektedir. İncelenen çalışmalarda sürdürülebilirlik kapsamında ele alınan projeler dikkate alınarak çalışma sonucunda elde edilen kazanımlara değinilmiştir.

Kayıhan ve Tönük (2011), temel eğitim binaları için sürdürülebilir tasarım destek modelinin kurgulanmasını inceleyen bu çalışmada, temel eğitim binalarının toplam sürdürülebilirlik kriterlerini; çevresel, ekonomik ve toplumsal tasarım olarak belirlemiştir. Temel eğitim binalarının, öğrencilere ve çevreye sürdürülebilirlik konularında eğitim sağlayabilmesi için gerekli tasarım kriterleri üzerinde incelemeler yapmışlardır. Saygın ve Ulusoy (2011) yaptıkları çalışmada geniş kapsamlı olan Sürdürülebilir Kampüs ilkeleri (etkin kaynak ve enerji kullanımı, atık yönetimi, geri dönüşümü olan malzeme kullanımı, su yönetimi, alternatif ulaşım yöntemleri gibi) arasından su kaynakları yönetimi konusunu ele almışlardır. İzmir Yüksek Teknoloji Enstitüsü (IYTE) kampüsünün mevcut durumunu yağmursuyu yönetimi açısından inceleyerek IYTE Mimarlık Fakültesi için açık alan tasarımı ve altyapı uygulamaları konularında yeşil altyapı önerileri geliştirmişlerdir. Esin ve Tekçe (2012) sürdürülebilir okullar için uyumlandırma süreçlerinde ve yapılabilecek yeni tasarımlarda önemli olan kriterleri iç hava kalitesi, günı̧ı̆ğından yararlanma stratejisi, enerjiyi verimli kullanma, ulaştırma, su, malzeme, arazi kullanımı ve ekoloji, inovasyon-yaratıcı çözümler başlıkları altında ele alınmaktadır. Okul yapılarının sürdürülebilirlik için değerlendirildiğinde model bir proje olması gerektiğine değinmişlerdir. Tonguç (2012), okul öncesi eğitim yapılarının tasarımlarında sürdürülebilirliği oluşturan faktörlerin potansiyellerini ve ne şekilde ele alındıklarını incelemiş ve uluslararası alanda örnekleri bulunan bu yapıların üzerinde incelemeler ve analizler yapmıştır. Çocuklara sağlanabilecek kaliteli eğitimin çevreye duyarlı özel eğitim yapılarında mümkün olabileceğine değinmiştir. Olszak (2012) yaptığı çalışmada Fransa Lille kentinde bulunan Katolik üniversitesinde sürdürülebilir bir kampüs uygulaması için "ekonomik etkinlik", "çevreye duyarlılık", "sosyal eşitlik" başlıkları ile ilgili 30 farklı kriteri ele almıştır. Kriterlere ait etkinlik değerleri sürdürülebilir kampüs gösterge skoru ile değerlendirmiştir. Çözüm sonucunda bazı kriterlerin puanını iyileştirmek için kampüste uygulanabilecek olası uygulamalara vurgu yapmıştır. Tan vd. (2014), Çin"de bulunan üniversitelerin sürdürülebilir yeşil kampüs uygulamalarına geçiş sürecindeki 30 yıllık geçmişini değerlendirerek öncelikle kampüs içerisinde tüketilen enerji miktarını gözlemlemişlerdir. Enerji ve kaynak verimliliği bakımından kampüsün gelişiminin Çin'de kapsamlı bir şekilde genişletildiği ve tüm bu girişimlerin ulusal hükümet tarafından güçlü bir şekilde desteklendiği sonucuna varmışlardır. Şahin ve Dostoğlu (2015) yaptıkları çalışmada okul yapıları için sürdürülebilir yapım kapsamında bir öğrenme aracı olarak sürdürülebilir tasarımın etkisine değindikten sonra, doğal ışıktan yararlanma, ssıtma, soğutma ve havalandırma yöntemleri, rüzgâr enerjisi, su koruma ve malzeme seçimi için sürdürülebilir okul tasarımında önem taşıyan konuları araştırmışlardır. Sürdürülebilir tasarım ilkelerinin dikkate alındığı uygulamaların Dünya"da ve Türkiyee de sayıca azlı̆̆ına değinerek son yıllarda konuya olan ilgide artış olduğunu vurgulamışlar ve çalışmalarında okul tasarımları için yardımcı bir kaynak sağlayabilmeyi amaçlamışlardır. Kocabaş ve Bademcioğlu (2016), çalışmalarında, sürdürülebilirliğin yapıları tasarlamanın yanı sıra bir yaşam tarzı olarak içselleştirilmesi gerektiğine ve okul binalarının ise bu bilincin yerleştirilmesi adına büyük önem taşıdığına değinmişlerdir. Bayramoğlu (2016) yaptı̆̆ çalışmada küresel 1sınma ve kuraklığın ortaya çıkardığ susuzluk sorunu ile peyzaj mimarlığı uygulama alanındaki bitkisel unsurların da negatif yönde etkilendiğine değinmiştir. Bu problemi, sürdürülebilir peyzaj düzenleme yaklaşımı ile ele alarak kuraklığın olumsuz etkilerini azaltmak için bir yaklaşım önerisi sunmuştur. Yaptığı 
çalışma ile etkin su kullanımı adına, Karadeniz Teknik Üniversitesi Kanuni Kampüsüec nde bulunan ana yol aksındaki orta refüj bitki gruplarının ve yeşil alanlarda kullanılan çim bitkilerinin kurakçıl peyzaj (xeriscape) yaklaşımı ile uygunluğunu belirleyerek alternatif çözüm önerileri getirmeyi amaçlamıştır. Günerhan ve Günerhan (2016) yaptıkları çalışmada sürdürülebilirlik konusunda üniversitelerin yaptıkları çalışmaları incelemişler ve Türkiye de üniversitelerin sürdürülebilirlik konusundaki yaklaşımlarının yetersizliğini ele alarak çalışmalarında "sürdürülebilir üniversite modeli" önermişlerdir. Sürdürülebilirliğin uzun bir süreç olduğuna değinerek bu süreçte oluşabilecek herhangi bir dirençle karşılaşılmaması için öğrencilere, çalışanlara ve paydaşlara konunun önemini iyi anlatılıp benimsenmesi üzerine vurgu yapmışlardır. Hajrasouliha (2017) yaptığı çalışmada üniversite kampüslerinin sürdürülebilir fiziksel özelliklerini değerlendirmek amacıyla, sürdürülebilir kampüs indeksi geliştirmiştir. Geliştirilen indeks, "kentleşme", "yeşil kampüs" ve "kampüs içerisinde yaşam" olmak üzere üç başlık altında toplam 10 sürdürülebilir gösterge kriterleri ile oluşturulmuştur. Çalışma sonucunda, tek yönlü Anova ve PostHoc analizi kullanılmış, devlet ve özel üniversitelerinin fiziksel kalite skorlarının bağımsız ortalamaları arasındaki farka ulaşılmıştır. Yapılan analiz sonucunda sürdürülebilirlik alanında özel üniversitelerin devlet üniversitelerine oranla daha yüksek kalite skoruna sahip olduğu sonucu elde edilmiştir. Filibeli vd. (2017) sürdürülebilir su yönetimi konusuna dikkat çekerek Dokuz Eylül Üniversitesi Tınaztepe Yerleşkesiende oluşan evsel nitelikteki atıksuyun kampüs alanında ihtiyaç duyulan yeşil alan sulama suyunun karşılanmasına yönelik bir çalışma gerçekleştirmiş̧lerdir. Çalışmalarında, üniversite kampüsünde mevcut olarak uygulanan evsel nitelikli atıksuların belediyeye ait kanalizasyon sistemine direkt iletilmesi yerine, uygun arıtma süreçleriyle arıtılması sayesinde en az sulama suyu kalitesine ait kriterleri karşılayacak seviyede arıtılmış su elde edilmesi planlanmıştır. Suyun kullanılabilirliğin araştırmışlar ve arıtma sistemi olarak membran biyoreaktör sisteminin kullanılabilirliği değerlendirmişlerdir. Dal ve Aşkın (2018) çalışmalarında, ülkemizde sayıları hızla artan üniversitelere ait kampüslerin, yeni yapılaşma süreçlerinde sürdürülebilir-ekolojik olma özelliği taşımaları konusunda bir farkındalık oluşturmayı amaçlamışlardır. Türkiye "deki 5 Devlet Üniversitesi ile 5 Vakıf Üniversitesie"nin sürdürülebilir-ekolojik kampüs olma kriterleri olan "Enerji Yönetimi”, "Sürdürülebilir Ulaşım”, “Atık Değerlendirme”, "Su Yönetimi”, “Çevre ve Peyzaj Yönetimi”, "Sürdürülebilir Eğitim” parametreleri açısından 10 farklı üniversite kampüsünü değerlendirmişlerdir. Tavşan ve Yanılmaz (2019) yaptıkları çalışmada yurtiçi ve yurtdışından, LEED ve BREEAM sertifikasyon sistemlerinin kabul ettiği ortak standartların dikkate alındığı 12 adet eğitim yapısını seçerek sürdürülebilir eğitim yapılarında en etkin sürdürülebilirlik kriterlerinin belirlenmesini amaçlamışlardır. En etkin kriterlerin ,iç mekân ortam kalitesiee ve „su başlıkları altında yer aldığını saptayarak bu kriterler doğrultusunda sürdürülebilir bir yaklaşım benimseyen eğitim yapılarının çocuklara ve gençlere erken yaşlarda farkındalık bilincinin kazandırılacağına değinmişlerdir. Süt vd. (2019) sürdürülebilirlik için önemli bir alan olan yeşil ulaşım problemini ele almışlardır. Üniversitelerde kampüs içi ulaşımın sağlanmasında çevre dostu araçların kullanımı önerilerek, öne çıkan üç alternatif arasından Analitik Hiyerarşi Prosesi (AHP) ve TOPSIS yöntemleri kullanılarak seçim gerçekleştirilmiş̧ir. Çevre dostu olmasıyla kampüs için en uygun ring araçlarının seçimi yapılarak sonuçlar değerlendirilmiştir. Değerlendirme motor özelliği, donanım, estetik görünüm, enerji verimliliği, hareket kabiliyeti, engelsiz ulaşım, maliyet ve çevre kriterleri göz önüne alınarak yapılmıştır. Güzelkokar ve Gelişen (2019) tarafından yapılan çalışmada küresel ısınma ve artan enerji maliyetleri sebebiyle sürdürülebilir yapıların popüler bir araştırma alanı haline geldiğine vurgu yaparak yeşil ve sürdürülebilir bina dönüşümlerini ülkemizde uygulamanın yollarını analiz etmişlerdir. Hamurcu ve Eren (2020), çalışmalarında elektrikli araçların sıfır egzoz emisyonu yayarak şehirler için daha temiz hava sağladıklarına değinerek elektrikli otobüs seçimi problemini incelemişlerdir. ÇKKV yöntemlerinden AHP ve TOPSIS kullanarak altı potansiyel alternatifi, yedi kriter altında değerlendirerek daha iyi performans gösteren elektrikli otobüsü belirlemişlerdir. Aydın ve Aydın (2020) yaptıkları çalışmada 2030 yılı Atina Dirençlilik Stratejisi ve İstanbul Kent Konseyi" nin sıcak dalgalarına dair fikir ve önerilerini kullanarak şehirleri serinletmek için yönetim stratejilerini belirlemeyi hedeflemişlerdir.

- Literatürde ilk defa Sürdürülebilir Yeşil Kampüsee geçiş sürecinde, belirlenen kriterler doğrultusunda proje alternatiflerinin önceliklendirilmesi ANP yöntemi ile yapılmıştır.

- Literatürde ilk defa Kırıkkale Üniversitesi Merkez Kampüsüe'nde, birden fazla Sürdürülebilir Yeşil Kampüs proje alternatifini kapsayan bir çalışma gerçekleştirilmiştir.

\section{ANP Yöntemi}

Saaty tarafından $1996^{\circ d}$ da ortaya atılan ANP yöntemi, karmaşık karar verme problemlerine çözüm yapılmasına olanak sağlamaktadır. ANP yöntemi, kriter ve alternatifler arasındaki geri besleme ile kümeler arasındaki ve küme içi bağımlılığı hesaba katarak çözüm sonucuna ulaşılan bir yöntemdir (Sarkis, 1998). Yapılan çalışmada literatürde 
yaygın bir şekilde kullanılan ÇKKV yöntemlerinden ANP yöntemi uygulanmıştır. ÇKKV yöntemleri, sağlık (Yapıcı vd., 2020; Oral, vd., 2021), lojistik (Oral vd., 2021) ve imalat (Yazıcı vd., 2021) gibi birçok sektörde farklı problem tiplerinde geniş uygulama alanına sahiptir. Çok kriterli karar verme problemlerinde literatürde en çok Analitik Hiyerarşi Prosesi kullanılmakla birlikte problemin kriterler arası ă̆ yapısından dolayı ANP yöntemi kullanılmıştır. Çalışmada ANP yönteminin kullanılmasının sebebi, modelleme aşamasındaki faktörler arasındaki bağımlılıklar ve faktör içindeki iç bağımlılıkların göz önüne alınmasıyla karar vermede daha etkin ve daha gerçekçi bir sonuç elde edilmesini sağlamaktır.

ANP yönteminin uygulama adımları aşağıda verilmiştir (Oral vd., 2021).

Adım 1: Problemin tanımlanması ve ağ yapısının oluşturulması.

Ele alınan karar problemi tanımlanarak hedef, alt kriterler, ana kriterler ve alternatifler belirlenmektedir.

Adım 2: Kriterlerin birbirleri ile olan ilişkilerin belirlenmesi.

Kriterlerin birbirleri arasındaki içsel, dışsal bağımlılıkları ve geri bildirimler ilişkilendirilmektedir (Görener, 2011).

Adım 3: Kriterler arası ikili karşılaştırmaların yapılması.

Kriterler arası ikili karşılaştırmalar, bir kriterin diğer bir kritere göre ne kadar önemli olduğunu belirlemek adına yapılmaktadır.

Adım 4: Matrislerin özvektörlerinin hesaplanması ve tutarlılık analizi.

Her bir kriter için tutarlılık indeksi (CI) ve tutarlılık oranı (CR) hesaplanmaktadır. CI, CR hesaplamaları için kullanılan formüller (1) ve (2) eede verilmiştir. En büyük özvektör değer olarak ifade edilir. "n" ise vektör boyutunu ifade etmektedir.

Tablo 1. RI değerleri

\begin{tabular}{|c|c|c|c|c|c|c|c|c|c|c|c|c|}
\hline $\mathrm{n}$ & 1 & 2 & 3 & 4 & 5 & 6 & 8 & 9 & 10 & 11 & 12 & 13 \\
\hline RI & 0 & 0 & 0,58 & 0,9 & 1,12 & 1,24 & 1,41 & 1,45 & 1,49 & 1,51 & 1,48 & 1,56 \\
\hline
\end{tabular}

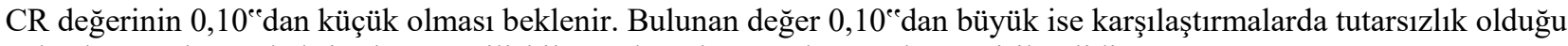
anlaşılır. Bu durumda kriterler arası ilişkiler ve karşılaştırmalar gözden geçirilmelidir.

Adım 5: Süper matrislerin oluşturulması.

Ana kriterler, alt kriterler ve alternatifler arasındaki tüm etkileşimler ve karşılaştırmalar göz önüne alınarak süper matrisler (ağırlıklandırılmamış, ağırlıklandırılmış ve limit) oluşturulmaktadır.

Adım 6: Kriter önem dereceleri belirlenerek en iyi alternatifin seçilmesi.

En iyi kriter ve alternatif, limit süper matrisi sonuçlarına göre en yüksek önem ağırllğına sahip olan kriter ve alternatiftir.

\section{Uygulama}

Ülkemizdeki üniversitelerin büyük bir alana ve yoğun öğrenci nüfusuna sahip oluşu ve gerçekleştirdikleri pek çok faaliyetler ile küçük bir şehir niteliğinde olmaları çevreye doğrudan ve dolaylı olarak olumsuz etkiler meydana getirmektedir. Bu olumsuz etkiler Kırıkkale Üniversitesi Merkez Kampüsü' nde sürdürülebilir odaklı projelere yönelme ihtiyacını ortaya çıkarmıştır. Bu çalışmada, literatürde kullanılan kriterler konunun uzmanı olan öğretim 
üyeleri ile mülakat yöntemi ile belirlenmiştir. Alternatifler ise ele alınan kampüsün ihtiyaçları doğrultusunda konununuzmanları ile belirlenmiştir. Yapılan çalışmada kullanılan yöntem adımlarının özetlendiği bir akış şemasıloluşturulmuş ve Şekil $1^{\text {ee }}$ de verilmiştir.

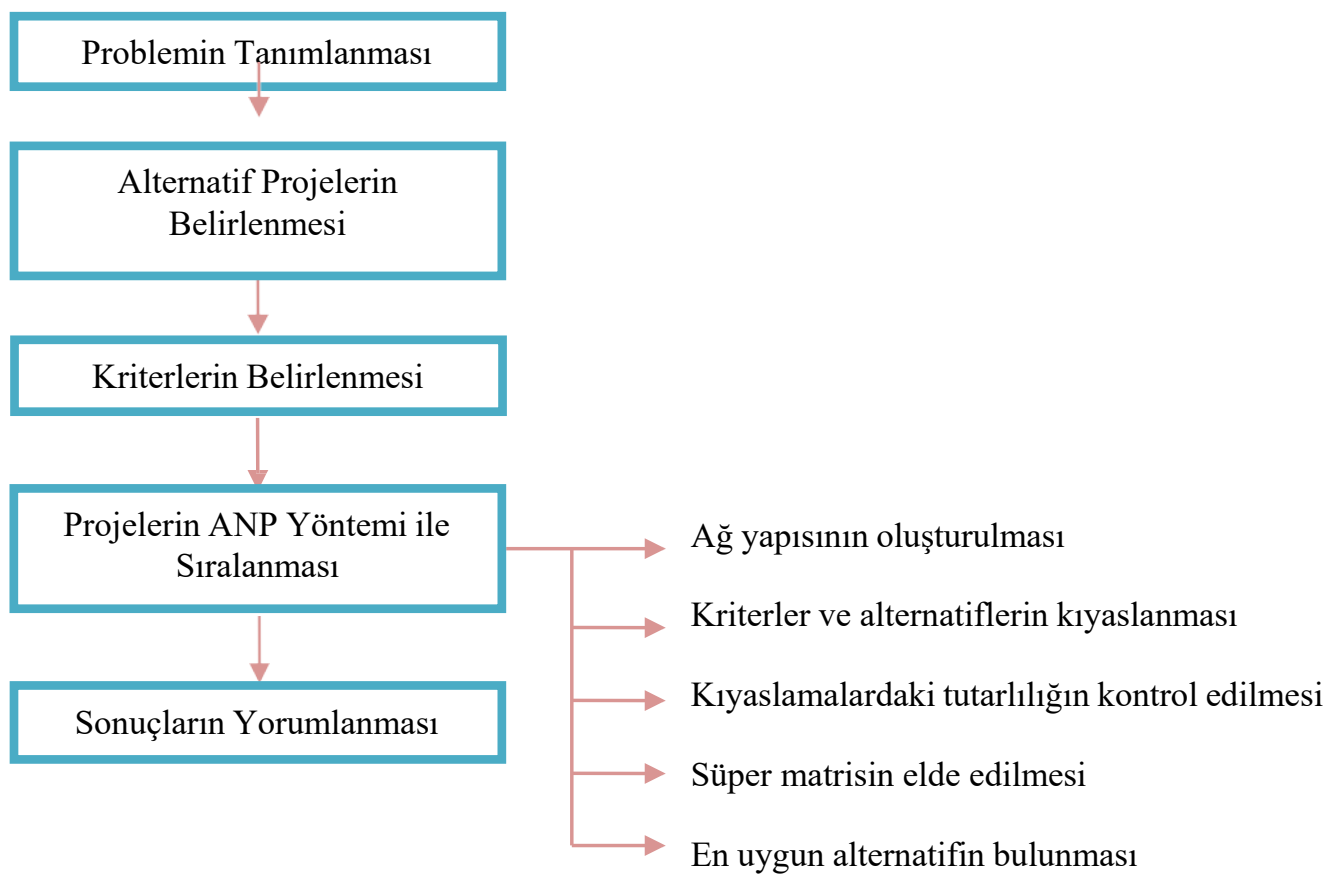

Şekil 1. Uygulama akış şeması

\subsection{Problemin Tanımlanması}

Hedef kitlenin yaşam kalitesini arttıran, ekolojik dengenin sürdürülebilirliğini sağlayacak bir yeşil kampüs projesinin hayata geçirilmesi hedeflemektedir. Kırıkkale Üniversitesi Merkez Kampüsü̈nde Sürdürülebilir Yeşil Kampüs Projesi için uygulanması öngörülen proje alternatifleri ve bununla ilişkili kriterlerin değerlendirilmesi ANP yöntemi kullanılarak yapılmıştır. Alternatifler ve açıklamaları aşağıda verilmiştir.

\subsubsection{Alternatifler}

Literatür incelendiğinde sürdürülebilir yeşil kampüs kapsamında küresel ısınma, enerji, su yönetimi ve tasarrufu, atık geri dönüşümü, yeşil ulaşım ve çevre gibi alanlarda uygulanabilir projelerin gerçekleştirildiği görülmüştür. Bundan hareketle bu çalışmada en çok uygulama alanına sahip yeşil çatı, dikey bahçe, elektrikli taşıtlar, güneş panelleri ve sürdürülebilir eğitim alternatif olarak seçilmiştir.

Yeşil Çatı Projesi (A1): Yeşil çatılar küresel ısınmanın neden ve sonuçlarının çoğuna çözüm üretebilen bir sistem önerisidir. Yeşil çatılar çoğunlukla su geçirmez bir membran, drenaj tabakası ve yalıtımın yapılması ile bitki örtüsü ve toprak tabakasının oluşturulması sonucu bina çatılarında yer almaktadır. Yeşil çatılar görsel zenginliğin yanı sıra enerji kullanımında tasarruf sağlanmasını, yapı içerisine 1S1 yönetimini sağlama özelliğine sahip yapılardır. Altyapı sistemlerine de su tutma özelliği sayesinde yardımcı olurlar. Sağladığı tüm bu faydalar göz önüne alındığında Kırıkkale Üniversitesi Merkez Kampüsüeende fakülte binaları ve öğrenci yurtlarına Yeşil Çatı uygulamasının yapılması önerilmiştir (Güzelkokar ve Gelişen, 2019; Kaya, Dal ve Aşkın, 2019).

Dikey Bahçe Projesi (A2): Dikey bahçeler havayı serinletmeye yardımcı olan yapılardır. Yerden tasarruf sağlayarak en dar alanlarda dahi yüzlerce bitki sayesinde orman etkisi yaratabilir. Kentsel 1sı adacıklarını, ani sıcaklık değişimlerini ve trafik gürültüsünü azaltmaya yardımcı olur. Sağladığı tüm bu faydalar göz önüne alındığında Kırıkkale Üniversitesi kampüsündeki fakülte binaları ve öğrenci yurtlarına Dikey Bahçe uygulamasının yapılması önerilmiştir (Aydın ve Aydın, 2020; Yıldız, 2014). 
Elektrikli Taşıtlar Projesi (A3): Elektrikli taşıtlar bir veya daha fazla elektrik motorunun bağlı olduğu bataryaya depoladığ 1 elektriği kullanılarak çalıştırılırlar. Zararlı bir atık üretmemeleri sebebiyle de şehirlerde temiz havaya katkıda bulunurlar. Elektrikli araçlar, yakıt tasarrufu sağlar ve karbon emisyonunu azaltır. Kırıkkale Üniversitesi kampüsünde kullanılan mevcut öğrenci taşıma ringlerinin tamamen elektrikli hale dönüştürülmesi önerilmiştir (Kaya, Dal ve Aşkın, 2019; Hamurcu ve Eren, 2020).

Güneş Panelleri Projesi (A4): Güneş panelleri, Güneşten gelen enerjiyi elektrik enerjisine dönüştüren bir sisteme sahiptirler. Güneş panellerinin üzerinde yer alan Güneş hücrelerinde, Güneş ışınları sayesinde doğru bir akım oluşur. Güneş panelleri yapılarından dolayı uzun süreler dayanabilir. İklim değişikliği üzerindeki kişisel etkileri azaltmaya yardımcı olmak adına karbon emisyonunu düşüren Güneş panellerini kullanılabilir. Enerji tasarrufu sağlamaları ile aynı zamanda çevreye de katkı sağlamış olunmaktadır. Tek bir Güneş enerjisi sistemi ile her yıl atmosfere salınan 7 tona kadar karbondioksit gazını ikame ederek azaltabilir. Doğal gaz ve kömür ile çalışan enerji santralleri büyük miktarlarda suya gereksinim duymaktadırlar. Güneş enerjisi sistemleri çalışmak için suya ihtiyaç duymamaları sebebiyle, yerel su kaynaklarına uygulanan baskının ve su kirliliğinin azalmasına olanak sağlar (Kaya, Dal ve Aşkın, 2019).

Sürdürülebilir Eğitim (A5): Üniversiteler, yol gösterici ve yenilikçi olma rollerinden dolayı sürdürülebilir bir yaşam anlayışının yaygınlaşmasına katkı sağlayan en önemli eğitim-öğretim kurumlarıdır. $\mathrm{Bu}$ sebeple Kırıkkale Üniversitesinde çevre ve doğa korunuşuyla ilgili derslerin eklenmesi, sosyal sorumluluk bilincini arttırmaya yönelik kulüplerinin bulunması, çevre konulu sergi, seminer, toplantı ve kongrelerin düzenlenmesi vb. faaliyetlerin gerçekleştirilmesi önerilmiştir (Kaya, Dal ve Aşkın, 2019).

\subsubsection{Kriterler}

Bu uygulamada ekonomik faktörler (K1), kaynak verimliliği (K2) ve hava kalitesine etki (K3) ana kriterler olarak, kurulum maliyetleri (K11), nitelikli iş gücü maliyetleri (K12), su verimliliği (K21), enerji verimliliği (K22), zaman (K23), karbon emisyonu (K31) ve oksijen üretimi (K32) alt kriterler olarak belirlenmiştir.

\section{Ekonomik Faktörler (K1)}

> Kurulum Maliyetleri (K11): Bu kriter yatırım, teknik ekipman ve yapı maliyetlerini kapsamaktadır. Yatırım alternatiflerinin hayata geçirilmesinde kurulum maliyetlerinin minimum düzeyde tutulması önemli bir ekonomik faktördür.

> Nitelikli İş Gücü Maliyetleri (K12): Genel tanımıyla her bir ürüne tekabül eden işçilik masraflarıdır. Kalifiye eleman ve katma değer sağlayan faaliyetleri kapsar. Uzmanlık gerektiren bu faaliyetler için ayrılan iş gücü maliyetleri önemli bir gider kalemi oluşturmaktadır.

\section{Kaynak Verimliliği (K2)}

$>\mathrm{Su}$ Verimliliği (K21): Geliştirilmiş ve yeni teknolojilerin kullanımı ile yaşam ve üretim kalitesini düşürmeden, daha az su kullanılarak aynı miktardaki işi yapabilmek adına gerçekleştirilecek projeler siralanmalidır.

$>$ Enerji Verimliliği (K22): Projelerin sürdürülebilirlik açısından ürün ve hizmetlerin sağlanması adına gereken enerji miktarını azaltmaya etkisi değerlendirilmesi gereken önemli bir kriterdir.

> Zaman (K23): Projeleri uygulamaya geçirmek için gerekli olan süreleri kapsamaktadır. Hızla gelişen iklim değişikliğinin önüne geçilebilmesi adına zaman kritik bir faktör olarak öne çıkmaktadır.

\section{Hava Kalitesine Etki (K3)}

> Karbon Emisyonu (K31): Ekolojik dengenin korunması adına kilit noktalardan biri olan karbon emisyonunun azaltılmasına katkı sağlayacak projelerin hayata geçirilmesi önemli bir kriter olarak karşımıza çıkmaktadır.

> Oksijen Üretimi (K32): Hava kalitesini oksijen açısından zenginleştirilme oranını kapsamaktadır. Yatırım alternatiflerinin oksijen üretimine katkı sağlayacak projeler olması sürdürülebilirlik açısından önemli bir kriterdir. 


\subsection{Yatırım Alternatiflerinin ANP Yöntemi ile Değerlendirilmesi}

Yapılan çalışmada Bölüm 2ede verilen ANP yöntemi adımları uygulanarak kriter ağırlıkları ve alternatifler değerlendirilmiştir. ANP yöntemi ile çözüme ulaşmak için Super Decisions paket programı kullanılmıştır. Çözüm ile

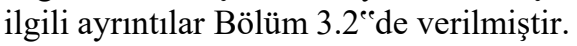

\subsubsection{Problemin ANP Yöntemi ile Çözümü}

ANP yönteminin birinci adımı ağ yapısının oluşturulmasıdır. Birbirini etkileyen alt kriterler birbiri ile, alternatifler ise

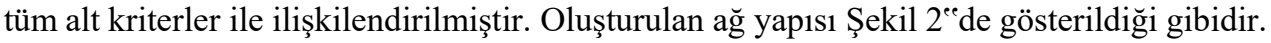

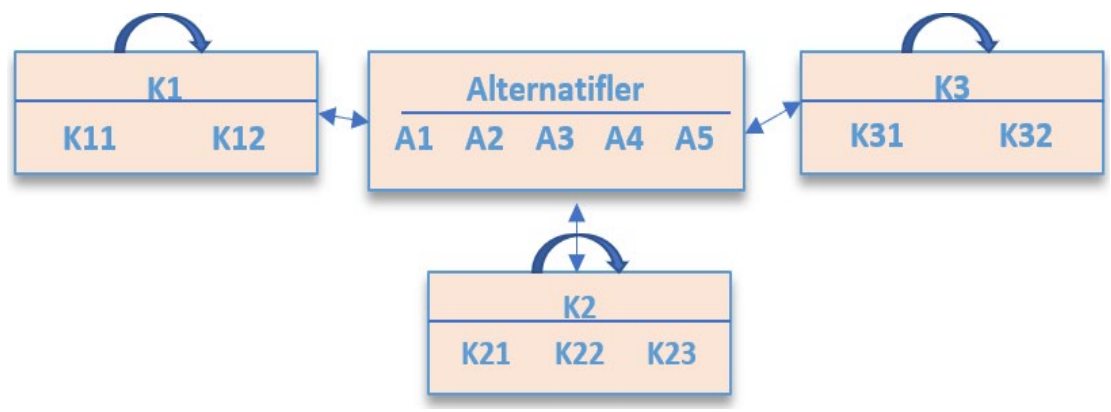

Şekil 2. ANP ağ yapısı

İlişki matrisi alt kriterlerin birbiri ile olan ilişkileri dikkate alınarak uzmanlar tarafından oluşturulmuştur. Alt kriterler

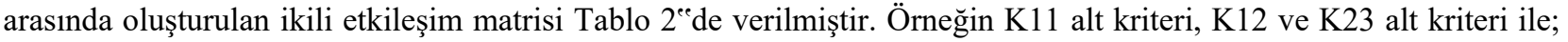
K23 alt kriteri, K21, K22, K31 ve K32 alt kriterleri ile etkileşim halindedir.

Tablo 2. İkili etkileşim matrisi

\begin{tabular}{|c|c|c|c|c|c|c|c|}
\hline & $\mathbf{K 1 1}$ & $\mathbf{K 1 2}$ & $\mathbf{K 2 1}$ & $\mathbf{K 2 2}$ & $\mathbf{K 2 3}$ & $\mathbf{K 3 1}$ & $\mathbf{K 3 2}$ \\
\hline $\mathbf{K} 11$ & - & $*$ & & & $*$ & & \\
\hline $\mathbf{K} 12$ & $*$ & - & & & $*$ & & \\
\hline K21 & & & - & $*$ & $*$ & & $*$ \\
\hline K22 & & & $*$ & - & $*$ & $*$ & $*$ \\
\hline K23 & & & $*$ & $*$ & - & $*$ & $*$ \\
\hline K31 & & & & $*$ & $*$ & - & $*$ \\
\hline K32 & & & $*$ & $*$ & $*$ & $*$ & - \\
\hline
\end{tabular}

Uzmanlar tarafından belirlenen kriter ve alternatifler arasındaki ilişkilere göre Super Decisions programına girilen ikili karşılaştırma matrisleri ile ağırlıklar elde edilmiştir. K11 alt kriterine ait ikili karşılaştırmalar Şekil $3^{\text {ette }}$ verilmiştir. 


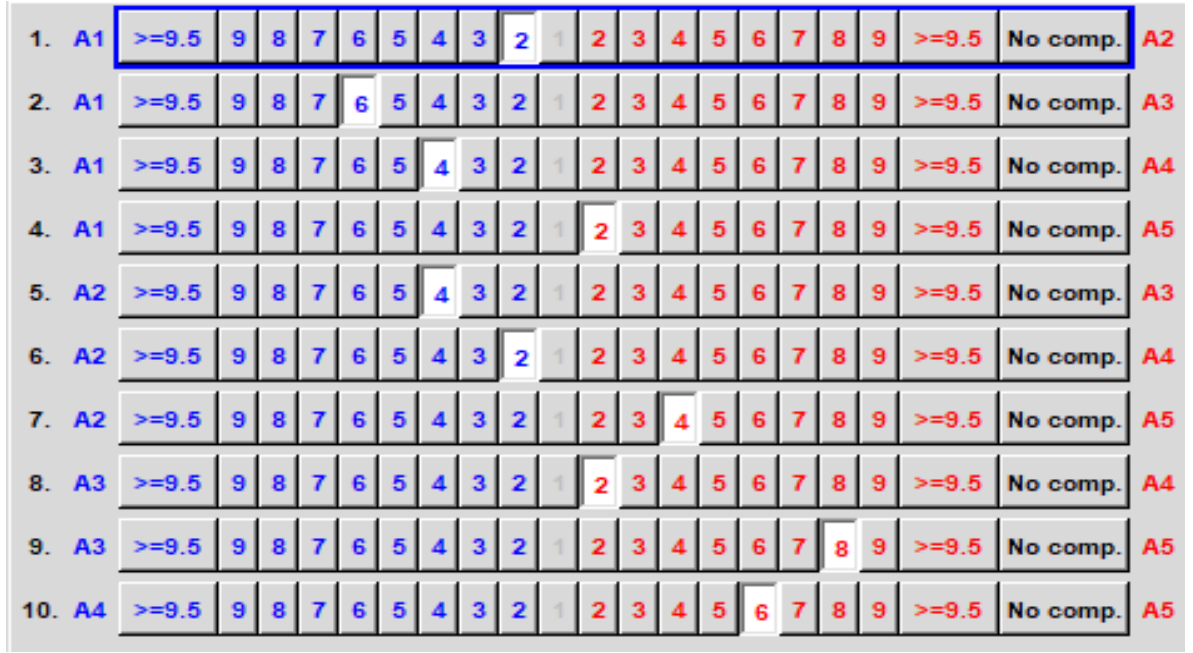

Şekil 3. K11 Alt Kriterine Ait İkili Karşılaştırmalar

Tutarlılık değerleri Tablo 3 "e verilmiştir.

Tablo 3. Tutarlılık değerleri

\begin{tabular}{|c|c|}
\hline Alt Kriterler & Tutarlılı Değerleri \\
\hline K11 & 0,01025 \\
\hline K12 & 0,09743 \\
\hline K21 & 0,07884 \\
\hline K22 & 0,07927 \\
\hline K23 & 0,07745 \\
\hline K31 & 0,07672 \\
\hline K32 & 0,08355 \\
\hline
\end{tabular}

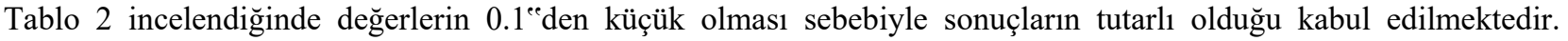
Ağırlıklandırılmamış süper matrisi ile limit süper matrisi de oluşturularak alternatif ve kriterlerin önem dereceleri elde edilmiştir. ANP yönteminden elde edilen ana ve alt kriter ağırlıkları Tablo 4 "te verilmiştir.

Tablo 4. Kriter ağırlıkları

\begin{tabular}{|c|c|c|c|}
\hline Ana Kriterler & Ă̆ırlıklar & Alt Kriterler & A ğırlıklar \\
\hline \multirow{2}{*}{ K1 } & \multirow{2}{*}{0,117} & $\mathbf{K 1 1}$ & 0,032 \\
& & $\mathbf{~ K 1 2}$ & 0,013 \\
\hline \multirow{3}{*}{ K2 } & \multirow{2}{*}{0,269} & $\mathbf{K 2 1}$ & 0,073 \\
\cline { 3 - 4 } & & $\mathbf{K 2 2}$ & 0,179 \\
\cline { 3 - 4 } & \multirow{2}{*}{$\mathbf{2}$ K3 } & $\mathbf{K 2 3}$ & 0,078 \\
\hline \multirow{2}{*}{0,614} & $\mathbf{K 3 1}$ & 0,313 \\
& & $\mathbf{K 3 2}$ & 0,312 \\
\hline
\end{tabular}

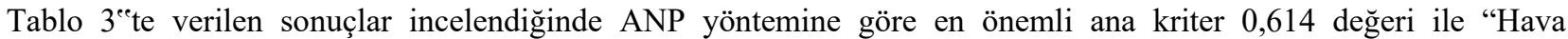
Kalitesine Etki” olmuştur. Daha sonra bu kriteri sırasıyla Kaynak Verimliliği ve Ekonomik Faktörler izlemiştir. ANP 
yöntemine göre en önemli alt kriter 0,313 değeri ile “Karbon Emisyonu” olmuştur. Daha sonra bu kriteri sırasıyla Oksijen Üretimi, Enerji Verimliliği, Zaman, Su Verimliliği, Kurulum Maliyetleri ve Nitelikli İş Gücü Maliyetleri kriterleri izlemiştir.

\section{SONUÇ:}

Yeşil kampüs çevresel ve sosyal açıdan ortaya çıkan olumsuz etkileri en aza indirmek için topluma sürdürülebilir yaşam biçimi konusunda öncülük etmektedir. $\mathrm{Bu}$ bağlamda hayata geçirilen çeşitli yeşil kampüs uygulamaları mevcuttur. Bu uygulamalardan yola çıkılarak Kırıkkale Üniversitesie`nde Sürdürülebilir Yeşil Kampüs için ANP

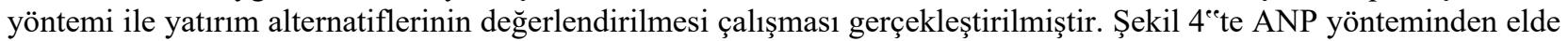
edilen alternatif ağırlıklarının sonuç grafiği verilmiştir.

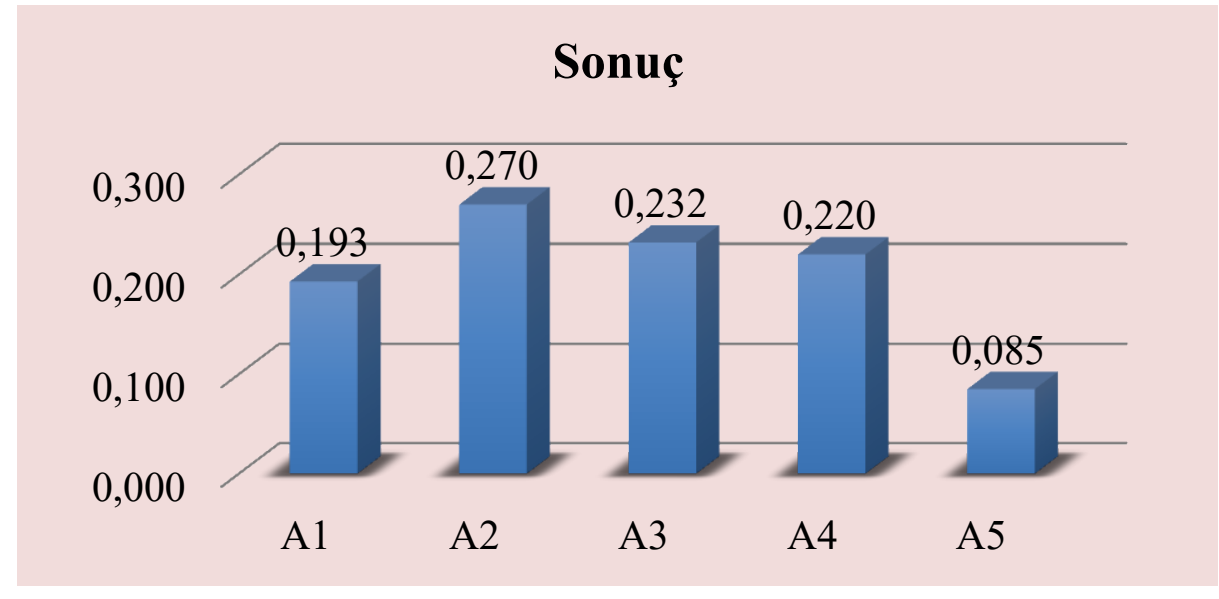

Şekil 4. Alternatif ağırlıkları

Alternatif sonuçları incelendiğinde hayata geçirilmesi planlanan ilk sürdürülebilir ekolojik proje 0,270 değeri ile "Dikey Bahçe Projesi” olmuştur. Daha sonra bu projeyi sırasıyla 0,232 değeriyle Elektrikli Taşıtlar, 0,220 değeriyle Güneş Panelleri, 0,193 değeriyle Yeşil Çatı ve 0,085 değeriyle Sürdürülebilir Eğitim projeleri izlemiştir.

Sürdürülebilir Kampüs Projesine geçiş sürecinde öncelikli olarak seçilen dikey bahçeler, bina, duvar, çit gibi düşey yapısal elemanların çeşitli bitkilerle kaplanmasıyla oluşmaktadır. Yapılan birçok araştırma sonucunda dikey bahçelerin iç mekan sıcaklığı ve nemini belirli oranlarda düşürerek harcanan enerji miktarını azalttığı görülmüştür (Othman ve Sahidin, 2015; Shafer 2000). Dikey bahçeler, doğal temiz hava sistemi gibi çalışır, daha iyi bir nefes alma olanağı ve genel olarak daha sağlıklı bir ortam sağlar. Ayrıca bina sakinleri için sessiz bir çalışma ortamı yaratarak gürültü kirliliğinin azaltılmasına yardımcı olmaktadır. Bina yüzeylerinde habitat oluşturarak farklı bitki türlerinin yetiştirilebilmesi ve bunun yanında diğer canlıların (kuş, böcek vb.) yaşamasına olanak tanıması gibi doğal yaşamı desteklemektedir (Develi Uyar, 2018).

Küresel iklim değişikliğinin olumsuz etkileriyle mücadele edilmesinde üniversite gibi büyük kurumların üzerlerine önemli sorumluluklar düşmektedir. Bu sorumluluklar yerine getirilirken etkili olan su verimliliğini sağlama, daha kısa sürede hayata geçirilebilecek sürdürülebilir projeler planlama ve oksijen üretimine fayda sağlama gibi kriterleri karşılayan öncelikli proje Dikey Bahçeler Projesi olmuştur. Tüm bu avantajlar göz önüne alındığında Kırıkkale Üniversitesi Merkez Kampüsüee nde Sürdürülebilir Yeşil Kampüs Projesinin ülke genelinde küresel iklim değişikliği konusuna dikkat çekerek farkındalık yaratmasına katkı sağlaması hedeflenmektedir.

Ülkemizde mevcut ve açılacak olan üniversitelerin, sürdürülebilir kampüs olma yolundaki gelişimlerinin izlenmesi ile geleceğe yönelik planlamalar yapılabilir. Dolayısıyla ANP yönteminden elde edilen sonuçlar doğrultusunda Dikey Bahçe Projesi; karbon emisyonunu azaltması, oksijen üretimi, su verimliliği ve enerji verimliliğine katkı sağlaması, kurulum maliyetlerinin uygunluğu ve projenin hayata geçirilmesi için kısa bir zamanın yeterli olması sebebiyle diğer yatırım alternatifleri ile karşılaştırıldığında sürdürülebilir ekolojik kampüs için önemli bir ilk adım olacaktır. Kriterler

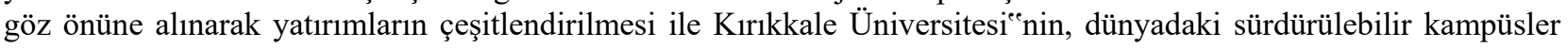
sıralamasında iyi bir konumda yer alması sağlanabilir. 
Sonuç olarak yapılan incelemeler kapsamında çalışmanın literatürde ilk defa Sürdürülebilir Yeşil Kampüs"e geçiş sürecinde, belirlenen kriterler doğrultusunda proje alternatiflerinin önceliklendirilmesi ANP yöntemi ile yapılmıştır. Bununla birlikte literatürde ilk defa Kırıkkale Üniversitesi Merkez Kampüsü"nde, birden fazla Sürdürülebilir Yeşil Kampüs proje alternatifini kapsayan bir çalışma gerçekleştirilmiştir.

Bu çalışmada olduğu gibi ÇKKV yöntemlerinden farklı yöntemler ile çözüm sonucu elde edilebilir. Farklı alternatif ve kriterler eklenip problemin analitiklik seviyesinin arttırılmasıyla literatüre katkı sağlanabilir.

\section{Etik Standart ile Uyumluluk}

Çıkar Çatışması: Yazarlar herhangi bir çıkar çatışmasının olmadığını beyan eder.

Etik Kurul İzni: Bu çalışma için etik kurul iznine gerek yoktur.

Finansal Destek: Yoktur.

\section{KAYNAKÇA:}

Aydın, B. ve Aydın, C. İ. (2020). Şehirleri Serinletmek İçin Yönetişim Stratejileri: Atina ve İstanbul Örnekleri. Umudun Yeri Yeşil Şehirler Çalıştayı, 1-18.

Bayramoğlu, E. (2016). Sürdürülebilir Peyzaj Düzenleme Yaklaşımı: KTÜ Kanuni Kampüsüénün Xeriscape Açısından Değerlendirilmesi. Artvin Çoruh Üniversitesi Orman Fakültesi Dergisi, 17(2), 119-127.

Develi Uyar, G. (2018). Dikey Yeşil Sistemler ve Uygulama Örnekleri. (Yüksek Lisans Tezi). Eskişehir: Anadolu Üniversitesi Fen Bilimleri Enstitüsü.

Filibeli, A., Büyükkamacı, N. ve Ayol, A. (2017). Yeşil Kampüs Uygulaması: Kampüs Atıksularının Sulama Amacıyla Yeniden Kullanımı. Yeşil Bina Sürdürülebilir Yapı Teknolojileri Dergisi, 46, 34-39.

Gelişen, G. ve Güzelkokar, O. (2019). Mevcut Yapıların Sürdürülebilir Yeşil Binalara Dönüştürülmesi. Ulusal Çevre Bilimleri Araştırma Dergisi, 2 (2), 76-90.

Görener, A. (2011). Bütünleşik ANP-VIKOR Yaklaşımı ile ERP Yazılımı Seçimi. Havacılık ve Uzay Teknolojileri Dergisi, 5 (1), 97-110.

Günerhan, S. A. ve Günerhan, H. (2016). Türkiye için Sürdürülebilir Üniversite Modeli. Mühendis ve Makina, 57(682), 54-62.

Hajrasouliha, A. (2017). Campus Score: Measuring University Campus Qualities. Landscape and Urban Planning, $158,166-176$.

Hamurcu, M. ve Eren, T. (2020). Electric Bus Selection with Multicriteria Decision Analysis for Green Transportation. Sustainability (Switzerland), 12 (7), 2777.

Kaya, S. K., Dal, M. ve Aşkın, A. (2019). Türkiye"deki Devlet ve Vakıf Üniversite Kampüslerinin SürdürülebilirEkolojik Parametreleri Açısından Karşılaştırılması. Balıkesir Üniversitesi Fen Bilimleri Enstitüsü Dergisi, 21 (1), 106125.

Kayıhan, K. S. ve Tönük, S. (2011). Sürdürülebilirlik Bilincinin İnşa Edileceği Binalar Olma Yönü ile Temel Eğitim Okulları. Politeknik Dergisi, 14(2), 163-171.

Kocabaş, İ. ve Bademcioğlu, M. (2016). Sustainability in Education Buildings. International Online Journal of Educational Sciences, 8(3), 180-192.

Esin, N. ve Tekçe, I. (2012). Eğitime Yeni Bakış ve Okul Binaları Tasarımındaki Yansımaları. Güney Mimarlık, 9, 32-33. 
Oral, N., Yumuşak, R. ve Eren, T. (2021). AHP ve ANP Yöntemleri Kullanılarak Tehlikeli Madde Depo Yeri Seçimi: Kırıkkale İlinde Bir Uygulama. Niğde Ömer Halisdemir Üniversitesi Mühendislik Bilimleri Dergisi, 10 (1), 115-124.

Oral, N., Yapıcı, S., Yumuşak, R. ve Eren, T. (2021). Pandemi Sürecinde Sürdürülebilir Tedarik Zinciri Yönetimi için İlaç Deposu ve Aşı Dağıtım Merkezi Yeri Seçimi. Politeknik Dergisi, 1-1.

Olszak, E. (2012). Composite Indicators for a Sustainable Campus—Design Rationale and Methodology: The Case of the Catholic Institute of Lille. Ecological indicators, 23, 573-577.

Othman, A. R. ve Sahidin, N. (2015). Vertical Greening Façade as Passive Approach in Sustainable Design. Elsevier Procedia Social and Behavioral Sciences, 222, 845-854.

Sarkis, J. (1998). Evaluating Environmentally Conscious Business Practices. European Journal of Operational Research, 107(1), 159-174.

Saygın, N. ve Ulusoy, P. (2011). Sürdürülebilir Kampüs Tasarımı İçin Yağmursuyu Yönetimi ve Yeşil Altyapı Teknikleri. Politeknik Dergisi, 14 (3), 223-231.

Shafer, C. S., Koo Lee, B. ve Turner, S. (2000). A Tale of Three Greenway Trails: User Perceptions Related to Quality of Life, Landscape Urban Planning, 49 (3-4), 163-178.

Süt, N. İ., Hamurcu, M. ve Eren, T. (2019). Kampüste Yeşil Ulaşım Uygulaması: Ring Araçlarının Seçimi İçin Bir Karar Verme Süreci. Gazi Mühendislik Bilimleri Dergisi (GMBD), 5 (1), 9-21.

Suwartha, N. ve Sari, R. F. (2013). Evaluating UI GreenMetric as a Tool to Support Green Universities Development: Assessment of The Year 2011 Ranking. Journal of Cleaner Production, 61, 46-53.

Şahin, B. E., ve Dostoğlu, N. (2015). Okul Binaları Tasarımında Sürdürülebilirlik. Uludağ University Journal of the Faculty of Engineering, 20(1), 75-91.

Tan, H., Chen, S., Shi, Q. ve Wang, L. (2014). Development of Green Campus in China. Journal of Cleaner Production, 64, 646-653.

Tavşan, F. ve Yanılmaz, Z. (2019). Eğitim Yapılarında Sürdürülebilir Yaklaşımlar. Sanat ve Tasarım Dergisi, (24), 359-383.

Tonguç, B. (2012). Sürdürülebilir Tasarımın Okul Öncesi Eğitim Yapıları Örneğinde İrdelenmesi. Yüksek Lisans Tezi, Kocaeli Üniversitesi, Fen Bilimleri Enstitüsü.

Yapıcı, S., Yumuşak, R. ve Eren, T. (2020). Çok Kriterli Karar Verme Yöntemleri ile Medikal Depo Yeri Seçimi. Trakya Üniversitesi İktisadi ve İdari Bilimler Fakültesi Dergisi, 9 (2), 203-221.

Yazıcı, E., Eren, T. ve Alakaş, H. (2021). Çok Ölçütlü Karar Verme Yöntemleri ile İşleme Merkezi Seçimi: İmalat İşletmesinde Uygulama. Endüstri Mühendisliği, 32 (1), 34-54.

Yıldız, M. (2014). Dikey Bahçe; Beton Yapıların Yeni Yeşil Yüzü, Ekoyapı Dergisi. Erişim Adresi: https://www.ekoyapidergisi.org/815-dikey-bahce-beton-yapilarin-yeni-yesil-yuzu.html 